\title{
Deep tubewell microbial water quality and access in arsenic mitigation programs in rural Bangladesh
}

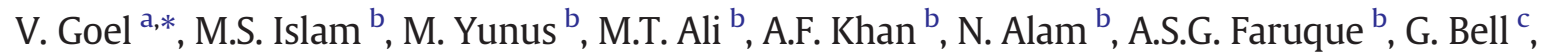 \\ M. Sobsey ${ }^{\mathrm{c}}$, M. Emch ${ }^{\mathrm{a}, \mathrm{c}, *}$ \\ a Department of Geography, University of North Carolina-Chapel Hill, Chapel Hill, USA \\ b International Centre for Diarrhoeal Disease Research, Bangladesh (icddr,b), Dhaka, Bangladesh \\ c Gillings School of Global Public Health, University of North Carolina-Chapel Hill, Chapel Hill, USA
}

H I G H L I G H T S

- Deep tubewell users on average have poorer water quality at point of use.

- Deep tubewell users store water longer, and travel longer distances.

- Storage times among deep tubewell users are impacted by distance and ownership status.

- Distance exacerbates contamination among deep tubewell users at point of use.

\section{A R T I C L E I N F O}

Article history:

Received 10 October 2018

Received in revised form 6 December 2018

Accepted 22 December 2018

Available online 24 December 2018

Editor: José Virgílio Cruz

Keywords:

Drinking water

Compartment bag test

E. coli

Point of use

Distance

Household water storage
G R A P H I C A L A B S T R A C T

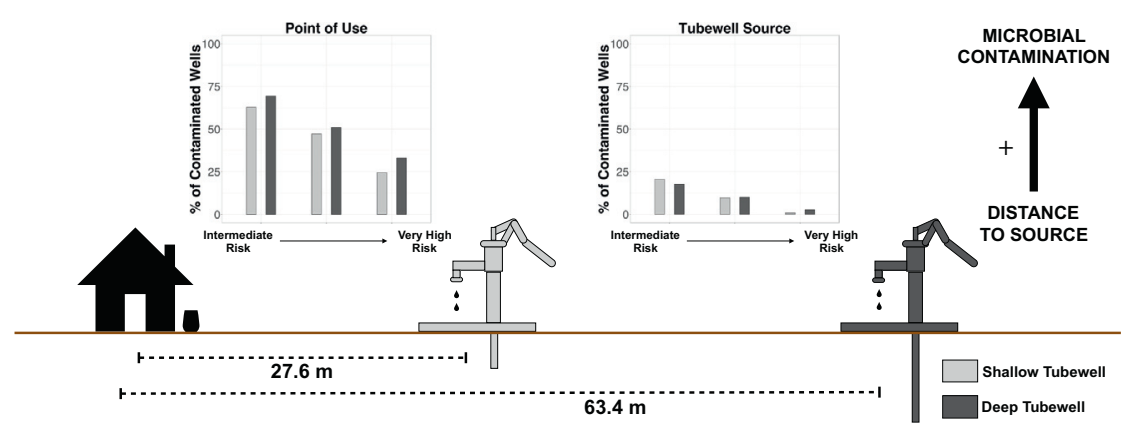

\footnotetext{
* Corresponding authors at: Carolina Population Center, 123 W Franklin St, Chapel Hill, NC 27516, USA. E-mail addresses: varung@live.unc.edu (V. Goel), emch@unc.edu (M. Emch).
} 


\section{Introduction}

Microbial contamination of drinking water quality is the second leading risk factor for diarrheal diseases which are the fifth leading cause of death in children under five years old worldwide (GBD 2016 Diarrhoeal Disease Collaborators, 2018; Roth et al., 2018). According to the 2016 Global Burden of Disease estimates, an estimated 1.1 billion episodes of diarrhea occur annually in these children, with south Asia and sub-Saharan Africa accounting for 90\% of the cases (GBD 2016 Diarrhoeal Disease Collaborators, 2018; GBD 2016 Mortality Collaborators, 2017). In an effort to reduce the diarrheal disease burden, public health efforts during the past 40 years in Bangladesh have led the majority of rural Bangladeshis to consume drinking water from groundwater aquifers using shallow tubewells rather than surface water. These shallow tubewells, with depths $<140 \mathrm{ft}$, are relatively inexpensive to install, require little labor and maintenance, and provide access to drinking water that is much less contaminated with microbial pathogens than surface water (Van Geen et al., 2003). However, many of these tubewells have exposed rural Bangladeshis to high levels of naturally occurring arsenic, resulting in increased all-cause mortality (Argos et al., 2010), and cancers of the lung, liver and bladder in adults (Naujokas et al., 2013; Smith et al., 2000).

To reduce exposure to arsenic, a common mitigation strategy for households is to switch from a contaminated shallow tubewell to nearby low-arsenic shallow tubewells (Ahmed et al., 2006; Van Geen et al., 2002). However, recent studies have shown that groundwater pumped from shallow low-arsenic wells is more likely to be contaminated than groundwater from shallow high-arsenic wells because of the nature of local hydrogeology and other factors such as high population density and poor sanitation and hygiene conditions (Islam et al., 2001; Leber et al., 2011; Van Geen et al., 2011). An increase in diarrhea was shown among rural households that obtain drinking water from shallow low arsenic wells, suggesting that avoiding arsenic contamination could increase exposure to microbial pathogens in shallow groundwater (Wu et al., 2011a). More generally, fecal contamination of shallow groundwater is one reason for the persistence of diarrheal disease in Bangladesh (Howard et al., 2006; Luby et al., 2008; Van Geen et al., 2011; Wu et al., 2011b).

Exposure to either high arsenic concentrations or high fecal microbe concentrations in shallow tubewells indicates the need for an alternative drinking water source. Besides switching to a low arsenic shallow tubewell, another common arsenic mitigation strategy is consuming drinking water from deep tubewells that tap into an aquifer usually $>500 \mathrm{ft}$ deep and mostly free of arsenic (Ravenscroft et al., 2013; Van Geen et al., 2003; Van Geen et al., 2007). As of 2010, approximately 165,000 deep tubewells had been installed throughout the country and have become a cornerstone of efforts to reduce arsenic exposure (DPHE, 2010). The low arsenic concentrations in deep tubewells have been shown to be stable over time, except when poorly constructed (Fendorf et al., 2010; Radloff et al., 2011; Van Geen et al., 2007). Deep tubewells have also demonstrated better microbial quality at source compared to shallow tubewells as E.coli and fecal coliform levels decrease with increased depth (Islam et al., 2001; Luby et al., 2008). Hence, it is possible that deep tubewells may provide added health benefits through better microbial quality in drinking water in addition to reduced arsenic exposure, resulting in lower incidence of diarrheal diseases, as compared to shallow tubewells (Escamilla et al., 2011; Winston et al., 2013).

However, a study by Field et al. (2011) found that switching to deep tubewells for arsenic mitigation from shallow tubewells led to a $27 \%$ increase in infant and child mortality rates in 155 villages in Barisal District, Bangladesh. While the specific mechanisms leading to higher mortality were not specified, there are possible mechanisms that could lead to poorer water quality and subsequent ill-health due to microbial contamination during collection, handling and storage of drinking water, even though the water may be relatively safe at source. The majority of rural Bangladeshis store their drinking water in a kolshi, an open-mouthed aluminum vessel with a narrow mouth but a wide rim, resulting in high contamination from external sources (Clasen et al., 2007a). Microbial contamination at the point of use (POU) in rural Bangladesh is common (Hoque et al., 2006) and has been closely associated with high diarrheal incidence in children, as opposed to microbial contamination at tubewell source (Howard et al., 2006; Luby et al., 2015; Trevett et al., 2005). Also, there is strong evidence from multiple studies, including randomized controlled trials in Bangladesh and other settings, that improving the microbial quality of water by chlorination at the source or POU by various methods reduces diarrheal disease risk (Clasen et al., 2007b; Ercumen et al., 2017; Fewtrell et al., 2005; Kremer et al., 2011).

Deep tubewell water might have higher microbial contamination levels at POU than privately owned shallow tubewells because households must travel farther to obtain drinking water and may store the water longer. Most of the deep tubewells are installed by the Department of Public Health and Engineering and non-governmental organizations rather than by households because they are much more expensive to install than shallow tubewells (Mosler et al., 2010; Van Geen et al., 2003). Since most deep tubewells are publically installed, they tend to be installed near a road in a central location of a village to maximize access. However, studies have shown that these tubewells are often inequitably located, and their use network is sparse as compared to shallow tubewells (Escamilla et al., 2011; van Geen et al., 2016; Winston et al., 2013). Additionally, rural Bangladeshis are only willing to walk up to $100-150 \mathrm{~m}$ on average to obtain water from deep tubewells when their shallow tubewells have high arsenic concentrations (Opar et al., 2007; Van Geen et al., 2003; Van Geen et al., 2002, 2003). Therefore, it is possible that longer distances to a deep tubewell will increase the duration of time people store drinking water, which may increase the risk of fecal contamination due to longer storage times and collection of larger volumes to minimize trips to the well (Brick et al., 2004; Copeland et al., 2009; Han et al., 1989; John et al., 2014; Levy et al., 2008; Lokuge et al., 2004; Momba and Kaleni, 2002; Oswald et al., 2007; Roberts et al., 2001; Shaheed et al., 2014; Wright et al., 2004). Given the conflicting results and uncertainties it is critically important to evaluate whether deep tubewells reduce risk of microbial contamination or if they increase risk because of increased storage times. Therefore, we conducted a cross sectional survey to assess the microbial water quality at source and POU for households using deep and shallow tubewells as their primary drinking water source, along with information about storage times and distance to their drinking water source.

\section{Materials and methods}

\subsection{Study area and design}

The study area, Matlab, Bangladesh, is a rural area located $50 \mathrm{~km}$ southeast of Dhaka. It is comprised of 142 villages with a population of approximately 238,000 people and 56,000 households. The households are arranged spatially based on patrilineal linkages in clusters called baris. A bari may contain anywhere from one to a dozen households, with an average of five to six households per bari. Generally, members in the same bari drink from a common tubewell. Baris that do not own a tubewell usually collect drinking water from wells owned by a neighboring bari or a community well such as those at a mosque or school. Matlab is one of the field sites for the International Centre for Diarrhoeal Disease Research, Bangladesh (icddr,b). The icddr,b manages a hospital that provides free treatment for diarrhea to all residents. Hospital and community-level records are maintained through a longitudinal Health and Demographic Surveillance System that has been in place since 1966. All individuals are assigned a unique identification number on entry into the area following birth or migration.

Survey data and water samples were collected in the Matlab study area during the dry season ranging from February to April 2018.The 
households were selected using a stratified random sample of households with strata based on previously collected data that identified whether they had been using deep or shallow tubewells as their primary drinking water source. We selected 250 households using a shallow tubewell and another 250 using a deep tubewell. Fig. 1 illustrates the spatial distribution of the sampled villages for the study. The sample includes households from 118 villages out of 142 villages and is spatially representative of the geography of Matlab. On completion of household visits, the final sample included 259 households currently obtaining their drinking water from shallow tubewells and 225 from deep tubewells. In addition to collecting water samples from both the drinking water source and household storage containers, we also collected data on storage time and distance to drinking water source. The selected households form the cohort of an ongoing longitudinal study, and further data and samples will be collected during the rainy season, and dry season the following year. The study received approval from the institutional review boards (IRB) of both University of North Carolina and icddr'b.

\subsection{Assessment of water quality}

The field team measured water quality by collecting two water samples from each household: one from the tubewell source, and the other from the household container at the POU. These samples were analyzed using the Compartment Bag Test (CBT) for the fecal indicator bacterium E. coli. E. coli is the fecal indicator bacterium recommended by the World Health Organization Guidelines for Drinking-water Quality (World Health Organisation (WHO), 2011). The CBT is a microbial water quality field test of simple design consisting of a clear plastic bag with five internal compartments of various volumes to determine a Most Probable Number (MPN) concentration of $E$. coli bacteria per $100 \mathrm{~mL}$ growing within a liquid growth medium containing an Indoxyl-Beta-Dglucuronide chromogenic substrate (X-gluc) for specific detection. E. coli fecal bacteria produce a blue color in the sample upon X-gluc hydrolysis due to their unique production of the beta-glucuronidase enzyme. The detection method provides quantitative next-day results for fecal bacteria concentrations between 0 and 100 E. coli per $100 \mathrm{~mL}$ (McMahan et al., 2011, 2012; Stauber et al., 2014). This test was shown independently to give comparable results to a standard membrane filter E. coli test for 270 diverse water samples (Stauber et al., 2014). We considered $E$. coli concentration to be a measure of water quality on both continuous and categorical scales based on a priori risk categories as per WHO guidelines - $<1 / 100 \mathrm{~mL}$ (safe), 1-10 /100 mL (intermediate risk), $11-100 / 100 \mathrm{~mL}$ (high risk) and $>100 / 100 \mathrm{~mL}$ (very high risk) (Brown et al., 2008). While any water sample with MPN E. coli values $>1 / 100 \mathrm{~mL}$ is considered contaminated, acceptable standards are higher in some countries.

We also conducted a pilot study to test the CBT in Matlab in the field and compare it to a standard membrane filter (MF) E. coli test using 74 kolshi and tubewell $100 \mathrm{~mL}$ samples. For the 74 tubewell and kolshi samples analyzed, the numbers of samples positive or negative for $E$. coli and the $E$. coli concentrations were similar by both the CBT and MF methods. When the data for $E$. coli positivity and negativity in tubewell and kolshi samples were analyzed by Fisher's Exact Test, the two-sided p-value was 0.0007 , indicating significant association. Sensitivity was 0.73 ( $95 \% \mathrm{CI}=0.54$ to 0.87 ), specificity was $0.70(95 \% \mathrm{CI}=0.53$ to 0.84 ), positive predictive value was $0.69(95 \% \mathrm{CI}=0.51$ to 0.83$)$ and negative predictive value was $0.74(95 \% \mathrm{CI}=0.57$ to 0.87$)$. Although the average

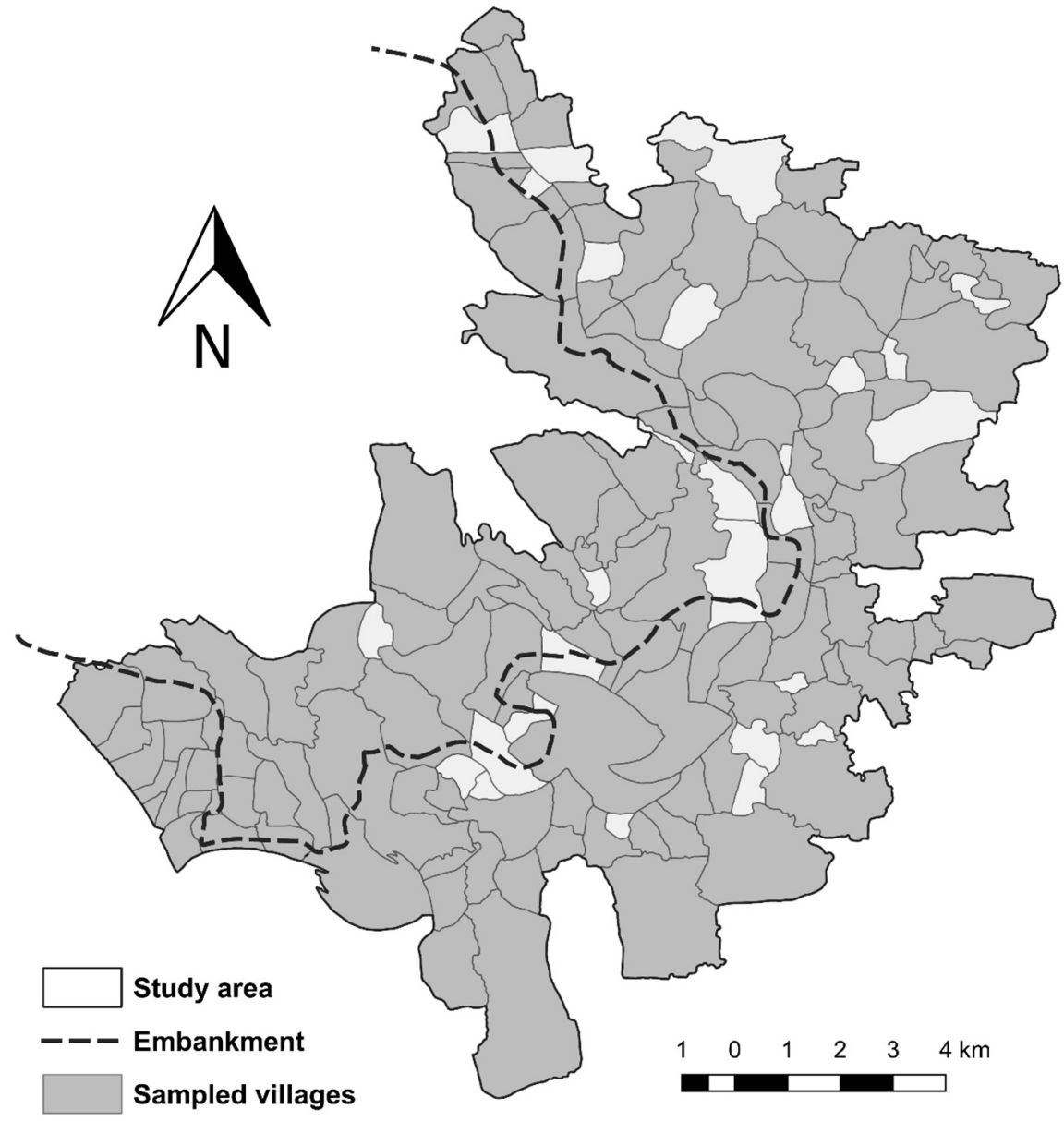

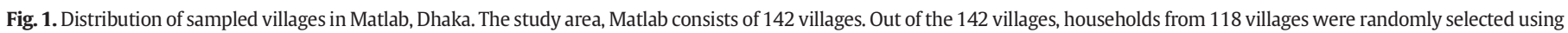
a stratified random sampling approach for recruiting deep and shallow tubewell users. 
and median concentrations of $E$. coli in water samples were somewhat higher by MF than by CBT in tubewell and kolshi samples and in pond water samples, there were no significant differences by MannWhitney $U$ tests ( $p$-value $=0.392$ ). Furthermore, the results of the two methods of analysis of tubewell and kolshi water samples were highly correlated, with $R=0.62$ by Pearson correlation on $\log _{10}$ transformed data and 0.58 by Spearman correlation on either arithmetic or $\log _{10}$ transformed data; all correlations were significant at $\mathrm{p}=0.01$. When the tubewell and kolshi E. coli concentration data from the CBT and MF were categorized into the WHO decimal concentration risk ranges $(0,1-10,11-100,>100$ per $100 \mathrm{~mL})$ and analyzed by Pearson Chi-Square, Likelihood Ratio and Linear-by-Linear Association, there were significant associations $(\mathrm{p}<0.0001)$ between the two water tests (CBT and MF) by all three methods of analysis. Overall, these results show equivalence in performance between the two tests that is similar to other comparisons of tests for fecal bacteria quantification in water. The advantage of the CBT test is that it is inexpensive and can be implemented in resource limited field settings, and thus, we chose the CBT for our water quality measurement for study.

\subsection{Assessment of water storage time}

Information on how long the water is stored in the container was collected through a survey by the field team while collecting water samples from the households. Respondents were asked to indicate the approximate time at which they last filled their main drinking water storage container. The storage time was then calculated as time elapsed between the last refill of the main drinking water storage container and the time of sample collection. In a few cases, where the main drinking water container was empty, respondents were asked to provide the time the container was last filled. Additionally, storage times were also categorized into an ordinal variable containing the categories of storage time $<2 \mathrm{~h}$, storage time between 2 and $24 \mathrm{~h}$, storage time between 24 and $48 \mathrm{~h}$, and storage time $>48 \mathrm{~h}$ to compare to $E$. coli growth curves or other contamination increases from previous studies and reduce chances for recall bias.

\subsection{Assessment of distance to tubewell}

Along with storage times, information about both the spatial distance, and the time taken to walk to the main drinking water source was collected. Field team members recorded global positioning system (GPS) points for the household location and main drinking water source, and also recorded the actual path taken by using the tracking feature of Garmin Etrex 30 GPS receivers. Field members also recorded the accuracy of each GPS location. Theoretically, the GPS model provides accuracy up to $3 \mathrm{~m}$. However, in the field the average accuracy of GPS units for household and tubewell location measurement was between 5 and $6 \mathrm{~m}$. In addition, the time taken to walk to the main drinking water source was estimated using a stopwatch. The time taken to the tubewell was measured by the field team members using their own gait without carrying any water collection utensils. Access to the tubewell for drinking water was assessed using two separate classification methods: maximum walking distance threshold and tubewell ownership. The first classification method divided tubewells that lie within or outside two distance bands of 100 and $150 \mathrm{~m}$. The second classification method was based on the ownership of the tubewell. Households were divided into those that owned a tubewell within their own bari premises, and those that used a tubewell owned by another bari or those that collected water from tubewells located within community areas such markets, schools or mosques.

\subsection{Statistical analysis of water quality and other characteristics}

We compared water quality and its relationship with other characteristics among the survey participants using prevalence ratios and difference in means measures. We first compared microbial contamination prevalence in source water and POU storage containers, followed by measuring water quality differences of shallow and deep tubewell users separately. We then compared characteristics such as storage time, distance to source, and ownership among the two strata. Finally, we analyzed water quality among deep tubewell users across different characteristics such as distance to water source and ownership of the tubewell and assessed whether storage times by distance or ownership were different for the two groups.

We tested all arithmetic variables and their log-transforms for normality using the Shapiro-Wilk test. Since all variables were not distributed normally, we chose non-parametric Mann-Whitney $U$ tests to compare differences in water quality, storage time, distance to source and ownership among shallow and deep tubewell users, and among deep tubewell users specifically. Mann-Whitney U tests are nonparametric tests that assess whether two sample means come from the same population using rank differences. For comparing differences in proportions of shallow and deep tubewell users based on distance and ownership, we used two-sided tests for equal or different proportions. We calculated unadjusted prevalence ratios of microbial contamination using Mantel-Haenszel tests based on the classification of cases across different exposures (Agresti, 2003). All analyses were conducted in $\mathrm{R}$ (version 3.50) ( $\mathrm{R}$ team et al., 2013).

\section{Results}

\subsection{Water quality}

Fig. 2 highlights the proportion of contaminated deep and shallow tubewells by cumulatively increasing levels of $E$. coli concentration at the tubewell source and at POU. Table 1 compares the characteristics of
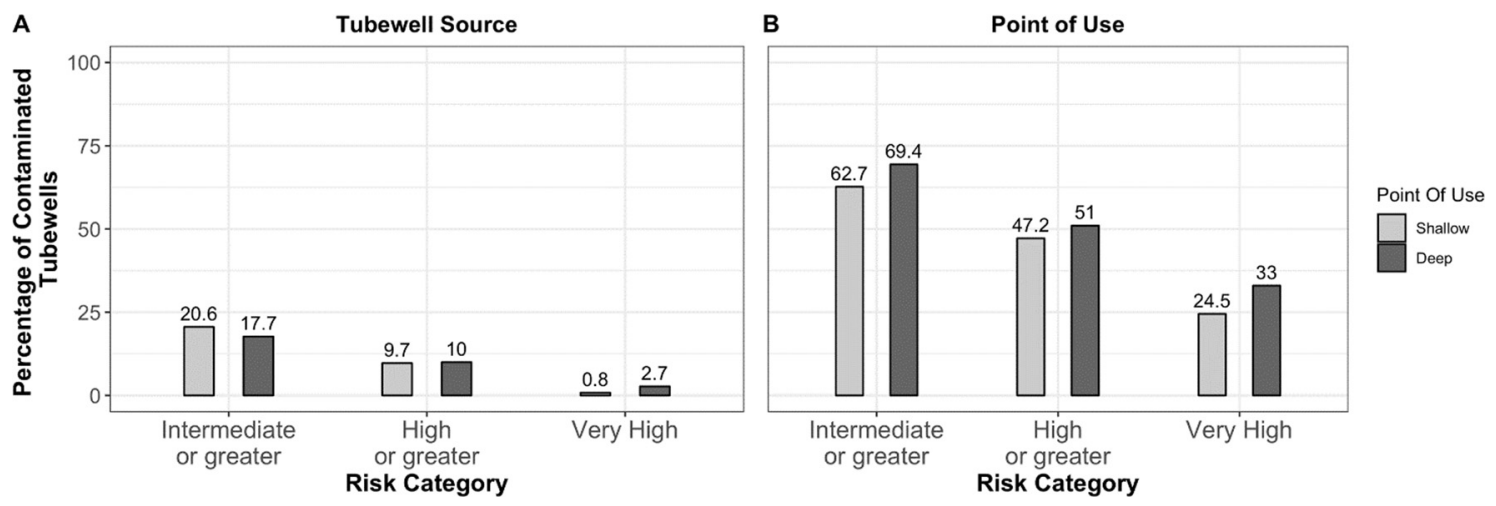

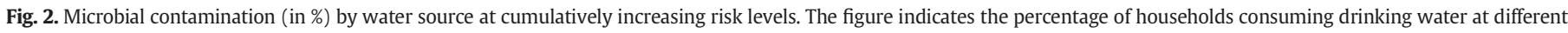

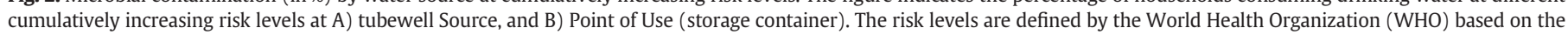
following classification: Intermediate: 1-10 CFU/100 mL, High: 11-100 CFU/100 mL, Very High: >100 CFU/100 mL. 
Table 1

Mean (standard deviation) of shallow and deep tubewell (TW) household water quality and related characteristics during the dry season $(n=484)$.

\begin{tabular}{|c|c|c|c|}
\hline Variables & $\begin{array}{l}\text { Shallow TW } \\
(\mathrm{n}=259)\end{array}$ & $\begin{array}{l}\text { Deep TW } \\
(\mathrm{n}=225)\end{array}$ & p-Value \\
\hline $\begin{array}{l}\text { Source water quality } \\
\text { Mean CFU/100 mL (SD) }\end{array}$ & $3.3(12.1)$ & $4.6(17.7)$ & $0.467^{\mathrm{a}}$ \\
\hline $\begin{array}{l}\text { Point of use water quality } \\
\text { Mean CFU/100 mL (SD) }\end{array}$ & $31.4(41.5)$ & 39.7 (44.6) & $0.059^{\mathrm{a}}$ \\
\hline $\begin{array}{l}\text { Other characteristics } \\
\text { Mean water storage time in hours (SD) } \\
\text { Time taken to source (seconds) } \\
\text { Distance to source (m) } \\
\text { Distance to source }>100 \mathrm{~m}(\%) \\
\text { Distance to source }>150 \mathrm{~m}(\%) \\
\text { Source not owned by bari (\%) }\end{array}$ & $\begin{array}{l}7.0(8.6) \\
27.9(32.9) \\
27.6(37.1) \\
5.4 \\
2.3 \\
14.7\end{array}$ & $\begin{array}{l}11.4(11.5) \\
62.0(60.1) \\
63.4(66.7) \\
20.0 \\
9.8 \\
52.9\end{array}$ & $\begin{array}{l}<0.001^{\mathrm{a}} \\
<0.001^{\mathrm{a}} \\
<0.001^{\mathrm{a}} \\
<0.001^{\mathrm{b}} \\
<0.001^{\mathrm{b}} \\
<0.001^{\mathrm{b}}\end{array}$ \\
\hline
\end{tabular}

Note: all calculations were made using complete cases, hence sample sizes differed slightly across each comparison.

a Non-parametric two-sided Wilcoxon Mann-U-Whitney Test with confidence level = 0.95 .

b Two-sided test of equal or given proportions with confidence level $=0.95$. deep tubewell households was 1.11 times $(95 \% \mathrm{CI}=0.97-1.27)$ the prevalence among shallow tubewell households.

\subsection{Storage time, distance and ownership}

Results in Table 1 show that both storage time and the distance to drinking water source on average were significantly greater for deep tubewell households. Deep tubewell households had an average drinking water storage time of $11.4 \mathrm{~h}$ compared to $7.0 \mathrm{~h}$ for shallow tubewells, which is a statistically significant difference $(\mathrm{p}<0.001)$. In addition, deep tubewell household members traveled distances up to 2.3 times farther compared to shallow tubewell households to collect drinking water, with an average deep tubewell located $63.4 \mathrm{~m}$ away from the households compared to $27 \mathrm{~m}$ for shallow tubewells. In addition, $20 \%$ of people from households accessing drinking water from deep tubewells walk more than the distance threshold of $100 \mathrm{~m}$, as compared to $5.4 \%$ of households collecting drinking water from shallow tubewells. Deep tubewell users procured drinking water from outside of their bari premises $52.9 \%$ of the time compared to $14.7 \%$ of the time for shallow tubewell users. The differences in proportions for deep and shallow tubewell users based on distance and ownership were statistically significant $(\mathrm{p}<0.001)$.

3.3. Deep tubewells: relationship between water quality, distance and storage times

Out of the 225 households collecting water from deep tubewells, 206 households were included in the complete case analytical sample for comparing microbial contamination among only the deep tubewell users based on distance and ownership characteristics. Table 2 displays the prevalence ratios for water sample E. coli positivity and Table 3 compares mean storage times among deep tubewell users based on distance, ownership, and presence of microbial contamination. Results from Table 2 show that households collecting water from deep tubewells $>100 \mathrm{~m}$ away were 1.24 times as likely as households with deep tubewells within $100 \mathrm{~m}$ to contain POU water at intermediate E. coli risk or higher $(95 \% \mathrm{CI}=1.04-1.48)$. Households with deep tubewells outside bari premises also had 1.14 times the prevalence of POU microbial contamination as those with tubewells inside bari premises, although the results were not statistically significant $(95 \% \mathrm{CI}=$ 0.94-1.37). In addition, analysis of storage times in Table 3 shows that households with deep tubewells $>100 \mathrm{~m}$ away also stored water on average for $16.2 \mathrm{~h}$ as compared to $10.5 \mathrm{~h}$ for tubewells within $100 \mathrm{~m}$ of the household. Longer average storage times were also observed among households with deep tubewells outside bari premises ( $14 \mathrm{~h}$ and $9 \mathrm{~h}$, respectively) as compared to those with tubewells within the bari compound. Mean storage times among households with microbial contamination compared to those with no POU microbial contamination were about $15 \%$ higher but not statistically significant $(12.2 \mathrm{~h}$ vs $10.6 \mathrm{~h})$.

Table 2

Comparison of microbial contamination prevalence (E.coli $\geq 1 \mathrm{CFU}$ per $100 \mathrm{~mL}$ ).

Exposure group

All storage containers

(POU)

Deep tubewell source

Deep tubewell POU

Deep tubewell greater than 100 meter

Deep tubewell not owned by bari
Reference group

All tubewell sources

Shallow tubewell source Shallow tubewell POU

Deep tubewell within 100 metres

Deep tubewell owned by bari of observations

890

477

439

206

206 with exposure (\%) without exposure (\%)
Prevalence ratio

3.40

0.86

1.11

1.24

1.14
Confidence interval (95\%)

$2.79-4.17$

$0.59-1.25$

$0.97-1.27$

$1.04-1.48$

$0.94-1.37$
p-Value 0.00

0.43

0.14

0.04

0.17 
Table 3

Comparison of storage times among deep tubewell users.

\begin{tabular}{|c|c|c|c|c|}
\hline Group 1 (n) & Group 2 (n) & $\begin{array}{l}\text { Group 1: Mean } \\
\text { (SD) }\end{array}$ & $\begin{array}{l}\text { Group 2: Mean } \\
\text { (SD) }\end{array}$ & p-Value ${ }^{a}$ \\
\hline Deep tubewell within 100 m from household $(n=162)$ & Deep tubewell >100 m from households $(n=44)$ & $10.5(11.2)$ & $16.2(12.4)$ & $<0.001$ \\
\hline Deep tubewell owned by bari $(n=93)$ & Deep tubewell not owned by bari $(\mathrm{n}=113)$ & $9.0(8.6)$ & $14.0(13.4)$ & $<0.001$ \\
\hline Deep tubewell POU without microbial contamination $(n=63)$ & Deep tubewell POU with microbial contamination $(n=143)$ & $10.6(12.7)$ & $12.2(11.3)$ & 0.133 \\
\hline
\end{tabular}

Note: all calculations were made using complete cases, hence sample sizes differed slightly across each comparison.

a Non-parametric two-sided Wilcoxon Mann-U-Whitney Test.

\section{Discussion}

During the dry season, microbial contamination of household water was common at POU, with approximately half of households drinking water at intermediate risk of contamination or higher, and almost a quarter of households drinking water at very high risk of contamination. The contamination at tubewell source was much lower, suggesting the increase in microbial contamination is largely occurring during water handling and storage as demonstrated in prior studies (Clasen et al., 2007b; Hoque et al., 2006). Results of water quality at source suggest that there was no discernible difference in microbial contamination between deep and shallow tubewells (Howard et al., 2006). Both shallow and deep tubewell households had significantly higher POU microbial contamination compared to the source. However, the microbial contamination among deep tubewell households was higher than shallow tubewell households for all risk levels of microbial contamination ranging from intermediate to very high risk. Given that deep tubewell users had significantly higher storage times and travel longer distances to collect drinking water, it raises the possibility that the sparse network of deep tubewell installations (Opar et al., 2007) and subsequent issues of access may compromise safe storage and result in increased risk of inadequate microbial quality at the POU.

Households traveling $>100 \mathrm{~m}$ to collect drinking water from a deep tubewell have a significantly higher prevalence of microbial contamination. It is possible that collecting water from public deep tubewells or from another bari may restrict access to drinking water as compared to households that procure drinking water from tubewells privately owned by members of the bari. However, water quality results suggest that although households with private deep tubewells have slightly lower prevalence of microbial contamination at the POU, the differences are not statistically significant. This may be explained by the fact that in places where networks of deep tubewells in many parts of Bangladesh are still sparse, and households do not have other safe low arsenic water options available nearby, shared or public tubewells may be the only source of available safe drinking water. In addition, although households with deep tubewells located $>100 \mathrm{~m}$ away from households have significantly higher storage times than households with nearby tubewells, there is no clear linear relationship between storage times and prevalence of microbial contamination. This suggests that there are other factors related to the storage environment such as the type of storage container, storage container cleaning method, volume of container and storage temperature that impact microbial contamination at the POU that may impact storage container use and its state of hygiene (Han et al., 1989; John et al., 2014; Levy et al., 2008; Momba and Kaleni, 2002). In addition, other factors not related directly to the storage environment - such as handwashing practices, household sanitation conditions, neighborhood sanitation access and conditions, water collection and handling practices - may have contributed to the microbial contamination incidents that occur and are cumulative during drinking water storage (Ercumen et al., 2017; Escamilla et al., 2013; Fewtrell et al., 2005; Wolf et al., 2018). Hence, further research that includes other covariates needs to be undertaken to disentangle the effect of different practices and processes from water handling to storage on POU microbial contamination among deep tubewell users, and identify the conditions under which the risk of microbial contamination is minimized.
In addition to omission of contextual covariates, there are other important limitations to the current analysis. Firstly, since the analysis is based on a one-time cross-sectional dataset, it does not take seasonality into account. Levels of fecal contamination at source have been shown to vary across dry and rainy seasons in different parts of Bangladesh (Fendorf et al., 2010; Islam et al., 2001; Luby et al., 2015; Zheng et al., 2005). Hence it is possible that differences in water quality at source among shallow and deep tubewell users may be different in the rainy season and modify the risk of microbial contamination at POU among deep tubewell users. Concentrations of $E$. coli in well water can vary and are sensitive to temporal fluctuations such as wet and dry seasons, and precipitation events and changes land-use conditions such as construction and farming practices. POU E. coli concentrations in water can also fluctuate widely across temporal scales and with handling and use practices. Hence, repeated measures of $E$. coli concentrations for each household across time would strengthen the analysis and provide more representative and robust results. In addition to those limitations, there is also possibility of recall bias among respondents when asked to provide storage time information based on the last time the drinking water storage container was filled. To minimize the effect of recall bias on results, we also transformed storage times to a categorical variable and checked for changes in effect size, magnitude and standard errors. Yet, results were consistent across different combinations. Similarly, we also analyzed results using travel time instead of distance to check for consistency of results. Both travel time and distance were almost perfectly linearly correlated $\left(R^{2}=0.93\right)$. However, we used distance for the final analysis due to its substantive significance based on previous literature. Finally, although we described the source and POU microbial contamination at different risk levels, we only considered prevalence ratios among those households with $E$. coli $<1 \mathrm{CFU} / 100 \mathrm{~mL}$ and those with at least $1 \mathrm{CFU} / 100 \mathrm{~mL}$ due to sample size considerations.

We would address these limitations in future studies based on the ongoing longitudinal study. We will include variables on the common risk factors of POU contamination related to household storage environment such as presence of feces, poultry and animals, and accessibility to hands of young children along with other water collection, handling and household sanitation environment variables. We will then determine correlates of POU contamination and also use these variables as controls to assess direct impact of storage time on microbial contamination. We will incorporate survey data and water quality results for the rainy season across the same households to examine whether the rainy season modifies the effect of distance and time on microbial contamination. We hypothesize that microbial quality will be poorer at source and POU during the rainy season and increasing distance to deep tubewells would have a higher adverse effect on contamination compared to the dry season. Additionally, we will expand our water quality outcomes to explore the efficacy of deep tubewells by using different microbial risk levels for tubewell source and POU. Subsequently, we will also analyze the relationship between deep tubewell access, storage time, POU microbial contamination and diarrheal disease outcomes.

\section{Conclusions}

Although deep tubewells are a mainstay of arsenic mitigation efforts in rural Bangladesh and may produce safer drinking water quality, it is not clear in what context and under what conditions they may be 
most effective. Given the spatial variation in both the microbial quality of groundwater and the heterogeneous distribution of deep tubewells providing drinking water to many rural Bangladeshi households, many contextual factors and conditions need to be considered before informed installation of deep tubewells can be scaled up. Overall, based on the dry season results, our findings suggest while deep tubewells may provide relatively safe water in microbial quality at source, their potential benefits may be nullified at POU and potentially even pose risks to users if they are located far from households, especially in areas with sparse safe drinking water options. Although, there is evidence of households storing drinking water for longer periods with increasing distance to source, potentially in response to minimizing time spent on collection of drinking water, factors both related to storage and to other parts of the water management and use process such as collection and handling, household sanitation access and conditions, and domestic and environmental hygiene, need to be considered to fully understand the conditions under which deep tubewells may provide safer and better drinking water as compared to shallow tubewells. Future research and policy efforts should target better allocation of deep tubewells in needed areas and minimize the time taken and distance traveled by rural Bangladeshis to ensure safe drinking water consumption as part of arsenic mitigation efforts.

\section{Declaration of interest}

Mark Sobsey, a co-investigator and author on this publication is an inventor on the technology being used in this research. Dr. Sobsey is also part owner of the company, Aquagenx LLC, which has licensed this technology. UNC-Chapel Hill has the patent on the technology and has a financial interest in the company.

\section{Acknowledgments}

This work was supported by the National Science Foundation [grant number BCS-1560970]. The funders had no role in study design, data collection and analysis, decision to publish, or preparation of the manuscript. The data used in this paper were collected with the support of icddr,b and its donors who provide unrestricted support to icddr,b for its operation and research. Current donors providing unrestricted support include the Government of the People's Republic of Bangladesh, Global Affairs Canada (GAC), the Swedish International Development Cooperative Agency (Sida) and the Department for International Development (UK Aid). We gratefully acknowledge these donors for their support and commitment to icddr,b's research effort. We also acknowledge the contribution of the primary data collection team consisting of Shahabbudin Babu and Md. Masnoon Kabir, and the whole team of community health workers and the field supervision team at the Matlab icddr'b surveillance site for their data collection efforts and inputs. We are also grateful to the Carolina Population Center for training support [T32 HD091058] and for general support [P2C HD050924].

\section{References}

Agresti, A., 2003. Categorical Data Analysis. John Wiley \& Sons.

Ahmed, M.F., Ahuja, S., Alauddin, M., Hug, S.J., Lloyd, J.R., Pfaff, A., Pichler, T., Saltikov, C., Stute, M., van Geen, A., 2006. Ensuring safe drinking water in Bangladesh. Science 314 (5806), 1687-1688.

Argos, M., Kalra, T., Rathouz, P.J., Chen, Y., Pierce, B., Parvez, F., Islam, T., Ahmed, A., Rakibuz-Zaman, M., Hasan, R., et al., 2010. Arsenic exposure from drinking water and all-cause and chronic-disease mortalities in Bangladesh (HEALS): a prospective cohort study. Lancet 376, 252-258.

Brick, T., Primrose, B., Chandrasekhar, R., Roy, S., Muliyil, J., Kang, G., 2004. Water contamination in urban south India: household storage practices and their implications for water safety and enteric infections. Int. J. Hyg. Environ. Health 207, 473-480.

Brown, J.M., Proum, S., Sobsey, M.D., 2008. Escherichia coli in household drinking water and diarrheal disease risk: evidence from Cambodia. Water Sci. Technol. 58, 757-763.

Clasen, T., Saeed, T.F., Boisson, S., Edmondson, P., Shipin, O., 2007a. Household water treatment using sodium dichloroisocy anurate ( $\mathrm{NaDCC}$ ) tablets: a randomized, controlled trial to assess microbiological effectiveness in Bangladesh. Am. J. Trop. Med. Hyg. 76, 187-192.

Clasen, T., Schmidt, W.-P., Rabie, T., Roberts, I., Cairncross, S., 2007b. Interventions to improve water quality for preventing diarrhoea: systematic review and meta-analysis. BMJ 334, 782-791.

Copeland, C.C., Beers, B.B., Thompson, M.R., Fitzgerald, R.P., Barrett, L.J., Sevilleja, J.E., Alencar, S., Lima, A.A.M., Guerrant, R.L., 2009. Faecal contamination of drinking water in a Brazilian shanty town: importance of household storage and new human faecal marker testing. J. Water Health 7, 324-331.

DPHE, J., 2010. Report on Situation Analysis of Arsenic Mitigation, 2009. Dhaka, Bangladesh.

Ercumen, A., Naser, A.M., Arnold, B.F., Unicomb, L., Colford, J.M., Luby, S.P., 2017. Can sanitary inspection surveys predict risk of microbiological contamination of groundwater sources? Evidence from shallow tubewells in rural Bangladesh. Am. J. Trop. Med. Hyg. 96, 561-568. https://doi.org/10.4269/ajtmh.16-0489.

Escamilla, V., Wagner, B., Yunus, M., Streatfield, P.K., Van Geen, A., Emch, M., 2011. Effect of deep tube well use on childhood diarrhoea in Bangladesh. Bull. World Health Organ. 89, 521-527.

Escamilla, V., Knappett, P.S.K., Yunus, M., Streatfield, P.K., Emch, M., 2013. Influence of latrine proximity and type on tubewell water quality and diarrheal disease in Bangladesh. Ann. Assoc. Am. Geogr. 103, 299-308.

Fendorf, S., Michael, H.A., van Geen, A., 2010. Spatial and temporal variations of groundwater arsenic in South and Southeast Asia. Science 328, 1123-1127.

Fewtrell, L., Kaufmann, R.B., Kay, D., Enanoria, W., Haller, L., Colford Jr., J.M., 2005. Water, sanitation, and hygiene interventions to reduce diarrhoea in less developed countries: a systematic review and meta-analysis. Lancet Infect. Dis. 5, 42-52.

Field, E., Glennerster, R., Hussam, R., 2011. Throwing the Baby Out with the Drinking Water: Unintended Consequences of Arsenic Mitigation Efforts in Bangladesh. Harvard Univ., Cambridge, MA.

GBD 2016 Diarrhoeal Disease Collaborators, 2018. Estimates of the global, regional, and national morbidity, mortality, and aetiologies of diarrhoea in 195 countries: a systematic analysis for the Global Burden of Disease Study 2016. Lancet Infect. Dis. 18, 1211-1228. https://doi.org/10.1016/S1473-3099(18)30362-1.

GBD 2016 Mortality Collaborators, 2017. Global, regional, and national age-sex specific mortality for 264 causes of death, 1980\&\#x2013;2016: a systematic analysis for the Global Burden of Disease Study 2016. Lancet 390, 1151-1210. https://doi.org/ 10.1016/S0140-6736(17)32152-9.

Han, A.M., Oo, K.N., Midorikawa, Y., Shwe, S., 1989. Contamination of drinking water during collection and storage. Trop. Geogr. Med. 41, 138-140.

Hoque, B.A., Hallman, K., Levy, J., Bouis, H., Ali, N., Khan, F., Khanam, S., Kabir, M., Hossain, S., Alam, M.S., 2006. Rural drinking water at supply and household levels: quality and management. Int. J. Hyg. Environ. Health 209, 451-460.

Howard, G., Ahmed, M.F., Shamsuddin, A.J., Mahmud, S.G., Deere, D., 2006. Risk assessment of arsenic mitigation options in Bangladesh. J. Health. Popul. Nutr. 24, 346.

Islam, M.S., Siddika, A., Khan, M.N.H., Goldar, M.M., Sadique, M.A., Kabir, A., Huq, A., Colwell, R.R., 2001. Microbiological analysis of tube-well water in a rural area of Bangladesh. Appl. Environ. Microbiol. 67, 3328-3330.

John, V., Jain, P., Rahate, M., Labhasetwar, P., 2014. Assessment of deterioration in water quality from source to household storage in semi-urban settings of developing countries. Environ. Monit. Assess. 186, 725-734.

Kremer, M., Leino, J., Miguel, E., Zwane, A.P., 2011. Spring cleaning: rural water impacts, valuation, and property rights institutions. Q. J. Econ. 126, 145-205.

Leber, J., Rahman, M.M., Ahmed, K.M., Mailloux, B., van Geen, A., 2011. Contrasting influence of geology on E. coli and arsenic in aquifers of Bangladesh. Groundwater 49, 111-123.

Levy, K., Nelson, K.L., Hubbard, A., Eisenberg, J.N.S., 2008. Following the water: a controlled study of drinking water storage in northern coastal Ecuador. Environ. Health Perspect. 116, 1533.

Lokuge, K.M., Smith, W., Caldwell, B., Dear, K., Milton, A.H., 2004. The effect of arsenic mitigation interventions on disease burden in Bangladesh. Environ. Health Perspect. 112, 1172.

Luby, S.P., Gupta, S.K., Sheikh, M.A., Johnston, R.B., Ram, P.K., Islam, M.S., 2008. Tubewell water quality and predictors of contamination in three flood-prone areas in Bangladesh. J. Appl. Microbiol. 105, 1002-1008.

Luby, S.P., Halder, A.K., Huda, T.M., Unicomb, L., Islam, M.S., Arnold, B.F., Johnston, R.B., 2015. Microbiological contamination of drinking water associated with subsequent child diarrhea. Am. J. Trop. Med. Hyg. 93, 904-911. https://doi.org/10.4269/ ajtmh.15-0274.

McMahan, L., Devine, A.A., Grunden, A.M., Sobsey, M.D., 2011. Validation of the H 2 S method to detect bacteria of fecal origin by cultured and molecular methods. Appl. Microbiol. Biotechnol. 92, 1287-1295.

McMahan, L., Grunden, A.M., Devine, A.A., Sobsey, M.D., 2012. Evaluation of a quantitative H2S MPN test for fecal microbes analysis of water using biochemical and molecular identification. Water Res. 46, 1693-1704

Momba, M.N.B., Kaleni, P., 2002. Regrowth and survival of indicator microorganisms on the surfaces of household containers used for the storage of drinking water in rural communities of South Africa. Water Res. 36, 3023-3028.

Mosler, HJ. Blöchliger, O.R Inauen, J. 2010. Personal, social, and situational factors influencing the consumption of drinking water from arsenic-safe deep tubewells in Bangladesh. J. Environ. Manag. 91, 1316-1323. https://doi.org/10.1016/j.jenvman.2010.02.012.

Naujokas, M.F., Anderson, B., Ahsan, H., Aposhian, H.V., Graziano, J.H., Thompson, C., Suk, W.A., 2013. The broad scope of health effects from chronic arsenic exposure: update on a worldwide public health problem. Environ. Health Perspect. 121, 295.

Opar, A., Pfaff, A., Seddique, A.A., Ahmed, K.M., Graziano, J.H., van Geen, A., 2007. Responses of 6500 households to arsenic mitigation in Araihazar, Bangladesh. Health Place $13,164-172$. 
Oswald, W.E., Lescano, A.G., Bern, C., Calderon, M.M., Cabrera, L., Gilman, R.H., 2007. Fecal contamination of drinking water within peri-urban households, Lima, Peru. Am. J. Trop. Med. Hyg. 77, 699-704.

Radloff, K.A., Zheng, Y., Michael, H.A., Stute, M., Bostick, B.C., Mihajlov, I., Bounds, M., Huq M.R., Choudhury, I., Rahman, M.W., et al., 2011. Arsenic migration to deep groundwater in Bangladesh influenced by adsorption and water demand. Nat. Geosci. 4, 793.

Ravenscroft, P., McArthur, J.M., Hoque, M.A., 2013. Stable groundwater quality in deep aquifers of southern Bangladesh: the case against sustainable abstraction. Sci. Total Environ. 454, 627-638.

Roberts, L., Chartier, Y., Chartier, O., Malenga, G., Toole, M., Rodka, H., 2001. Keeping clean water clean in a Malawi refugee camp: a randomized intervention trial. Bull. World Health Organ. 79, 280-287.

Roth, G.A., Abate, D., Abate, K.H., Abay, S.M., Abbafati, C., Abbasi, N., Abbastabar, H., AbdAllah, F., Abdela, J., Abdelalim, A., et al., 2018. Global, regional, and national agesex-specific mortality for 282 causes of death in 195 countries and territories, 1980-2017: a systematic analysis for the Global Burden of Disease Study 2017. Lancet 392, 1736-1788.

Shaheed, A., Orgill, J., Ratana, C., Montgomery, M.A., Jeuland, M.A., Brown, J., 2014. Water quality risks of 'improved 'water sources: evidence from Cambodia. Tropical Med. Int Health 19, 186-194.

Smith, A.H., Lingas, E.O., Rahman, M., 2000. Contamination of drinking-water by arsenic in Bangladesh: a public health emergency. Bull. World Health Organ. 78, 1093-1103.

Stauber, C., Miller, C., Cantrell, B., Kroell, K., 2014. Evaluation of the compartment bag test for the detection of Escherichia coli in water. J. Microbiol. Methods 99, 66-70.

Team, R.C, et al., 2013. R: A Language and Environment for Statistical Computing.

Trevett, A.F., Carter, R.C., Tyrrel, S.F., 2005. The importance of domestic water quality management in the context of faecal-oral disease transmission. J. Water Health 3, 259-270.

Van Geen, A., Ahsan, H., Horneman, A.H., Dhar, R.K., Zheng, Y., Hussain, I., Ahmed, K.M., Gelman, A., Stute, M., Simpson, H.J., et al., 2002. Promotion of well-switching to mitigate the current arsenic crisis in Bangladesh. Bull. World Health Organ. 80, 732-737.

Van Geen, A., Ahmed, K.M., Seddique, A.A., Shamsudduha, M., 2003. Community wells to mitigate the arsenic crisis in Bangladesh. Bull. World Health Organ. 81, 632-638.

Van Geen, A., Zheng, Y., Versteeg, R., Stute, M., Horneman, A., Dhar, R., Steckler, M., Gelman, A., Small, C., Ahsan, H., Graziano, J.H., Hussain, I., Ahmed, K.M., 2003. Spatial variability of arsenic in 6000 tube wells in a $25 \mathrm{~km} 2 \mathrm{area}$ of Bangladesh. Water Resour. Res. 39, 1-16. https://doi.org/10.1029/2002WR001617.
Van Geen, A., Cheng, Z., Jia, Q., Seddique, A.A., Rahman, M.W., Rahman, M.M., Ahmed, K.M., 2007. Monitoring 51 community wells in Araihazar, Bangladesh, for up to 5 years: implications for arsenic mitigation. J. Environ. Sci. Health A 42, 1729-1740.

Van Geen, A., Ahmed, K.M., Akita, Y., Alam, M.J., Culligan, P.J., Emch, M., Escamilla, V., Feighery, J., Ferguson, A.S., Knappett, P., et al., 2011. Fecal contamination of shallow tubewells in Bangladesh inversely related to arsenic. Environ. Sci. Technol. 45, 1199-1205.

van Geen, A., Ahmed, K.M., Ahmed, E.B., Choudhury, I., Mozumder, M.R., Bostick, B.C., Mailloux, B.J., 2016. Inequitable allocation of deep community wells for reducing arsenic exposure in Bangladesh. J. Water Sanit. Hyg. Dev. 6, 142-150. https://doi.org/ 10.2166/washdev.2015.115.

Winston, J.J., Escamilla, V., Perez-Heydrich, C., Carrel, M., Yunus, M., Streatfield, P.K., Emch, M., 2013. Protective benefits of deep tube wells against childhood diarrhea in Matlab, Bangladesh. Am. J. Public Health 103, 1287-1291.

Wolf, J., Hunter, P.R., Freeman, M.C., Cumming, O., Clasen, T., Bartram, J., Higgins, J.P.T. Johnston, R., Medlicott, K., Boisson, S., Prüss-Ustün, A., 2018. Impact of drinking water, sanitation and hand washing with soap on childhood diarrhoeal disease: updated meta-analysis and -regression. Trop. Med. Int. Health 23, 508-525. https:/ doi.org/10.1111/tmi.13051.

World Health Organisation (WHO), 2011. Guidelines for drinking-water quality. WHO Chron. 38, 104-108.

Wright, J., Gundry, S., Conroy, R., 2004. Household drinking water in developing countries: a systematic review of microbiological contamination between source and point-of-use. Tropical Med. Int. Health 9, 106-117.

Wu, J., van Geen, A., Ahmed, K.M., Alam, Y.A.J., Culligan, P.J., Escamilla, V., Feighery, J. Ferguson, A.S., Knappett, P., Mailloux, B.J., et al., 2011a. Increase in diarrheal disease associated with arsenic mitigation in Bangladesh. PLoS One e29593, 6.

Wu, J., Yunus, M., Streatfield, P.K., Van Geen, A., Escamilla, V., Akita, Y., Serre, M., Emch, M. 2011b. Impact of tubewell access and tubewell depth on childhood diarrhea in Matlab, Bangladesh. Environ. Health 10, 109

Zheng, Y., Van Geen, A., Stute, M., Dhar, R., Mo, Z., Cheng, Z., Horneman, A., Gavrieli, I., Simpson, H.J., Versteeg, R., et al., 2005. Geochemical and hydrogeological contrasts between shallow and deeper aquifers in two villages of Araihazar, Bangladesh: implications for deeper aquifers as drinking water sources. Geochim. Cosmochim. Acta 69, 5203-5218 